\title{
Gamma Knife in the Treatment of Pituitary Adenomas: Results of a Single Center
}

\author{
F.A. Zeiler, M. Bigder, A. Kaufmann, P.J. McDonald, D. Fewer, J. Butler, \\ G. Schroeder, M. West
}

\begin{abstract}
Introduction: Gamma Knife (GK) radiosurgery for pituitary adenomas can offer a means of tumor and biologic control with acceptable risk and low complication rates. Methods: Retrospective review of all the patients treated at our center with GK for pituitary adenomas from Nov 2003 to June 2011. Results: We treated a total of 86 patients. Ten were lost to follow-up. Mean follow was 32.8 months. There were 21 (24.4\%) growth hormone secreting adenomas (GH), 8 (9.3\%) prolactinomas (PRL), 8 (9.3\%) adrenocorticotropic hormone secreting (ACTH) adenomas, $2(2.3 \%)$ follicle stimulating hormone/luteinizing hormone secreting $(\mathrm{FSH} / \mathrm{LH})$ adenomas, and $47(54.7 \%)$ null cell pituitary adenomas that were treated. Average maximum tumor diameter and volume was $2.21 \mathrm{~cm}$ and $5.41 \mathrm{~cm}^{3}$, respectively. The average dose to the $50 \%$ isodose line was 14.2 Gy and 23.6 Gy for secreting and non-secreting adenomas respectively. Mean maximal optic nerve dose was $8.87 \mathrm{~Gy}$. Local control rate was 75 of 76 (98.7\%), for those with followup. Thirty-three (43.4\%) patients experienced arrest of tumor growth, while $42(55.2 \%)$ patients experienced tumor regression. Of the 39 patients with secreting pituitary tumors, 6 were lost to follow-up. Improved endocrine status occurred in 16 (50.0\%), while 14 $(43.8 \%)$ demonstrated stability of hormone status on continued pre-operative medical management. Permanent complications included: panhypopituitarism (4), hypothyroidism (4), hypocortisolemia (1), diabetes insipidus (1), apoplexy (1), visual field defect (2), and diplopia (1). Conclusions: Gamma Knife radiosurgery is a safe and effective means of achieving tumor growth control and endocrine remission/ stability in pituitary adenomas.
\end{abstract}

RÉSUMÉ: Le scalpel gamma dans le traitement des adénomes pituitaires : résultats chez des patients traités dans un même centre. Contexte : La radiochirurgie par scalpel gamma (SG) pour traiter des adénomes pituitaires peut offrir un contrôle de la tumeur et un contrôle biologique comportant un niveau de risque acceptable et un faible taux de complications. Méthode : Nous avons effectué une revue rétrospective des dossiers de tous les patients traités dans notre centre au moyen du SG pour des adénomes pituitaires de novembre 2003 à juin 2011. Résultats : Nous avons traité un total de 86 patients. Dix ont été perdus au suivi. Le suivi moyen était de 32,8 mois. Parmi les adénomes, 21 étaient des adénomes qui sécrétaient de l'hormone de croissance $(24,4 \%), 8$ étaient des prolactinomes (9,3\%), 8 sécrétaient de l'hormone adrénocorticotrope (9,3\%), 2 sécrétaient de la gonadotrophine A/gonadotrophine $\mathrm{B}(2,3 \%)$ et 47 étaient des adénomes pituitaires non-fonctionnels. Le diamètre maximal moyen et le volume moyen étaient $2,21 \mathrm{~cm}$ et 5,41 cm3 respectivement. La dose moyenne à la ligne isodose 50\% était 14,2 Gy et 23,6 Gy pour les adénomes sécrétoires et non sécrétoires respectivement. La dose maximale moyenne délivrée au nerf optique était 8,87Gy. Le taux de contrôle local de la tumeur était de 75 sur 76 ( $98,7 \%$ ) chez les patients pour qui le suivi était disponible. Chez 33 patients $(43,4 \%)$ la tumeur a cessé de croître et chez 42 patients $(55,2 \%)$ la tumeur a régressé. Parmi les 39 patients qui avaient une tumeur sécrétante, 6 ont été perdus au suivi. L'état endocrinien s'est amélioré chez 16 (50\%) et il est demeuré stable chez 14 patients dont le traitement médical préchirurgical a été maintenu. Les complications permanentes ont été les suivantes : le panhypopituitarisme (4), l'hypothyroïdie (4), l'hypocortisolémie (1), le diabète insipide (1), l'apoplexie (1), un défaut du champ visuel (2) et de la diplopie (1). Conclusions : La radiochirurgie par scalpel gamma est un moyen sûr et efficace de contrôler la croissance de la tumeur et de parvenir à une rémission endocrinienne/à la stabilisation des adénomes pituitaires.

Can J Neurol Sci. 2013; 40: 546-552

The treatment of pituitary adenomas is complex and multimodal. Treatment is indicated for hormone hypersecretion, disturbance of visual function, tumor growth and other neurologic sequellae secondary to mass effect. Classically, for those patients with pituitary adenomas, treatment has consisted of surgical resection and/or medical management of those secretory tumors.

Surgical approaches consist of transsphenoidal and formal craniotomy, amongst others, in order to debulk and remove as much tumor as possible, with the goal of tumor cure and improvement in neurological function and endocrine status.
Radiation therapy has been used in the past as an adjunct to treatment of recurrent and aggressive pituitary tumors, with mixed results. With the introduction of stereotactic radiosurgery,

From the Section of Neurosurgery, Department of Surgery (FAZ, MB, AK, PJM, DF, MW), Department of Radiation Oncology (JB, GS), University of Manitoba,

Winnipeg, Manitoba, Canada.

Received October 9, 2012. Final Revisions Submitted January 4, 2013. Correspondence to: Frederick A. Zeiler, Section of Neurosurgery, University of Manitoba, Health Sciences Center, GB-1 820 Sherbrook Street, Winnipeg, Manitoba, R3A 1R9, Canada. Email: umzeiler@cc.umanitba.ca. 
the ability to focus radiation dosing with sub-millimeter accuracy has allowed us to target pituitary adenomas for treatment with excellent results for tumor growth control and stabilization of endocrine function ${ }^{1,2}$.

Transsphenoidal approaches, whether microsurgical or endoscopic transnasal, are currently the gold standard surgical treatment modality for pituitary adenomas. Stereotactic radiosurgery (SRS) has generally been reserved for those patients with recurrence or residual tumor, and those patients medically unfit to undergo the physiologic stress of an operation. The indications for SRS are expanding as experience with the technique increases.

Complication rates described with Gamma Knife (GK) for pituitary adenomas are quite variable, with the most common being pituitary axis disorders, ranging from $0-72 \%{ }^{2}$. Radiation induced optic neuropathy, parasellar cranial neuropathy and cavernous carotid injury have been described but are relatively rare.

We describe our institutional experience with GK SRS in the treatment of pituitary adenomas from November 2003 to June 2011, with the goal to define our local growth control rates, endocrine remission rates, and complications.

\section{MethodS}

Between November 2003 and June 2011, 86 patients with pituitary adenomas underwent GK radiosurgery at the Health Sciences Center in Winnipeg, Manitoba. We retrospectively reviewed the records of these patients and recorded data on: age, sex, tumour diameter and volume, GK treatment parameters, complications, time until tumour response, local control rates, and clinical/endocrine outcomes. Follow-up on this patient population was accrued up to Dec 2011, with this data retrospectively accumulated from telephone contact, neuroimaging and neurosurgical clinic chart review. Local research ethics board approval was obtained prior to starting this study.

\section{ResUlts}

\section{Patient Demographics and Pituitary Adenoma Characteristics}

There were a total of 86 patients identified as being treated for pituitary adenomas with GK during the review. These eightysix patients received a single GK treatment at our institution, with none having had previous SRS. Procedures for tumor debulking were performed in 56 of the 86 patients $(65.1 \%)$, prior to GK, with ten patients $(11.6 \%)$ having two prior transsphendoidal operations. These surgical approaches included transsphenoidal resection in 50 patients $(58 \%)$, and craniotomy in six patients $(7.0 \%)$ for those tumors with significant parasellar/suprasellar extension. Average time from operation to GK treatment was 59.8 months. The average age at treatment was 55 years (range: $5-81$ ). Forty-six patients $(53 \%)$ were male and 40 patients $(47 \%)$ female. Average follow-up time was 32.8 months (range: $2-79$ months), with ten patients lost to followup. The median follow-up time was 35 months. Patient demographics for the 76 patients with follow-up are displayed in Table 1. Data pertaining to those patients lost to follow up can be seen in Table 2.

Of the ten patients lost to follow-up, all were referred to our facility by out of province physicians. They were subsequently lost to post-treatment follow up after returning to their respective provinces. Telephone contact was attempted on multiple occasions using the available contact information on file, but was unsuccessful.

Patients typically had multiple clinical presentations. Clinical manifestations on initial diagnosis were: visual field

Table 1: Demographic data of patients with follow-up

\begin{tabular}{lcc}
\hline Demographic Category & Male & Total Patient Population With Follow-Up $(\mathrm{n}=76)$ \\
\hline Age & Female & $19-81$ (average: 55.8$)$ \\
Sex & 33 \\
Average Tumour Total Volume $\left(\mathrm{cm}^{3}\right)$ & 5.41 \\
Average Tumour Diameter $(\mathrm{cm})$ & 2.21 \\
Average \% Coverage & 94.4 \\
Average 50\% Isodose Line Dose (Gy) for Secreting tumors & 24.7 \\
Average 50\% Isodose Line Dose (Gy) for Non-secreting tumors & 14.2 \\
Average Time to Decrease in Tumour Size (months) & 12.7 \\
Total Number With Tumor Growth Control & 75 \\
Total Number of Permanent Complications & 14 \\
\hline
\end{tabular}

$\mathrm{n}=$ number $; \mathrm{cm}=$ centimetre $; \mathrm{Gy}=$ gray 
Table 2: Characteristics of patients lost to follow-up

\begin{tabular}{lllll}
\hline Sex & Presentation & Location & Function & $\begin{array}{l}\text { Diameter of } \\
\text { Tumour }(\mathrm{cm})\end{array}$ \\
\hline F & Acromegaly & Sella, Suprasellar & GH & 1.8 \\
F & Cushing's Disease & Sella, Suprasellar, Lt Cav Sinus & ACTH & 2.3 \\
F & Amenorrhea & Sella & PRL & 1.95 \\
F & H/A, blurred vision & Sella, Suprasellar, Cavernous Sinus & Null & 3.51 \\
F & Cushing's Disease & Sella & ACTH & 1.5 \\
M & Dizzy, Deteriorating Lt vision & Sella, Suprasellar, Optic Chiasm & Null & 2.4 \\
F & H/A, fatigue & Sella, Supra, Cavernous Sinus & Null & 3.52 \\
M & Visual Blurring & Sella, Suprasellar & Null & 1.8 \\
M & Cushing's Disease & Sella & ACTH & 2.1 \\
F & Cushing's Disease & Sella, Rt Cav Sinus & ACTH & 1.4 \\
\hline
\end{tabular}

$\mathrm{F}=$ female, $\mathrm{M}=$ male, $\mathrm{Lt}=$ left, $\mathrm{Rt}=$ right, $\mathrm{Cav}=$ cavernous, $\mathrm{GH}=$ Growth Hormone, $\mathrm{ACTH}=$ Adrenocorticotropic Hormone, PRL $=$ Prolactin, Null $=$ Non-functioning

defect (20), acromegaly (18), headache (17), diplopia (7), Cushing's disease (7), blurred vision (5), amenorrhea (5), low libido (3), apoplexy (2), Addison's disease (1), diabetes insipidus (1), and relative afferent papillary defect (1). Nine patients had their pituitary adenoma discovered incidentally secondary to cranial imaging for unrelated complaints.

All were selected for treatment due to tumor progression or recurrence on follow up imaging. Refractory endocrinopathy was a factor in deciding to treat those patients with secreting adenomas, but all had demonstrated some interval change in size on pre-treatment imaging according to radiology interpretation, though some were quite small.

Eighty-one patients $(94.2 \%)$ had adenomas within the sella turcica (with the remaining five having tumor burden extra-sellar as a result of previous surgical debulking), while tumor extension into the suprasellar cistern occurred in $53(61.6 \%)$, into the cavernous sinus in $53(61.6 \%)$, into the sphenoid sinus in $9(10.4 \%)$, into the clivus in $5(5.8 \%)$, and the middle fossa region in $2(2.3 \%)$. The optic apparatus was compressed in $21(24.4 \%)$ patients. The average maximum diameter of the pituitary adenoma was $2.21 \mathrm{~cm}$ (range: $0.22-4.08 \mathrm{~cm}$ ), and the average tumor volume was $5.41 \mathrm{~cm}^{3}$ (range: $0.33-14.3 \mathrm{~cm}^{3}$ ).

Forty-seven $(45.3 \%)$ of the 86 patients treated had nonsecreting pituitary adenomas. Of the remaining tumors there were $21(24.4 \%)$ growth hormone $(\mathrm{GH})$ secreting, $8(9.3 \%)$ prolactin (PRL) secreting, $8(9.3 \%)$ adrenocorticotropic hormone (ACTH) secreting, and 2 (2.3\%) LH/FSH secreting adenomas. All patients with secreting tumors were on hormone modulating medications prior to treatment with GK, with the exception of the LH/FSH secreting adenomas. Hormone modulating medications were withheld temporarily prior to treatment with the GK.

\section{Treatment Characteristics}

Gamma Knife treatment planning was performed using magnetic resonance imaging (MRI) and computed tomography (CT) in 33 of $86(38.4 \%)$, and only MRI in 53 (61.6\%). Gamma
Knife treatment parameters consisted of an average maximum tumor dose of $36.8 \mathrm{~Gy}$ (range from 25 to $60 \mathrm{~Gy}$ ). The average number of collimator shots was 15.6 per treatment. The prescription dose to the $50 \%$ isodose line was $18.5 \mathrm{~Gy}$ (range from 12 to $35 \mathrm{~Gy}$ ). The average $50 \%$ isodose line dose for nonsecreting adenomas was $14.2 \mathrm{~Gy}$ (range of 12 to $18 \mathrm{~Gy}$ ). The average maximum dose for non-secreting adenomas was 28.6 Gy (range of 24 to $32 \mathrm{~Gy}$ ). The average $50 \%$ isodose line dosage for secreting adenomas was 23.6 Gy (range from 13 to $35 \mathrm{~Gy}$ ), with the average maximum dose for secreting adenomas being 46.8 Gy (range from 26 to $70 \mathrm{~Gy}$ ). The average total volume covered (TVC) was $4.7 \mathrm{~cm}^{3}$ (range: $0.33-12.1 \mathrm{~cm}^{3}$ ), with average percent coverage of $94.4 \%$ (range: $82-100 \%$ ). Eightyfour patients $(97.7 \%)$ had a recorded a maximal dose to the optic nerve $(\mathrm{ON})$ apparatus that was on average 8.9 Gy (range: $3.2-$ 12.2 Gy). Twenty-eight patients (32.5\%) had an ON dose recorded greater than or equal to $10 \mathrm{~Gy}$. Thirteen $(15.1 \%)$ patients had $\mathrm{ON}$ doses recorded a greater than or equal to $11 \mathrm{~Gy}$. Ten $(11.6 \%)$ patients had $\mathrm{ON}$ doses recorded at greater than or equal to $12 \mathrm{~Gy}$.

Patients received post-treatment follow-up phone interviews within two weeks of GK treatment. Follow-up clinic visits were conducted six to eight weeks post treatment. Imaging was conducted at three and nine months post-GK, and then yearly with MRI to assess tumor control, all with follow-up clinic visits with the treating neurosurgeon.

\section{Overall Tumor Growth Control}

Tumor control, which was defined as the absence of lesion growth, or decrease in size, on follow-up imaging occurred in $75 / 76$ (98.6\%) of the patients with follow up; $42(55.3 \%)$ demonstrated regression and $33(43.4 \%)$ stability in tumor size. The average time until change in adenoma size post-GK was 12.6 months.

Only one patient $(1.3 \%)$ demonstrated mild tumor growth despite GK treatment documented at approximately $3 \mathrm{~mm}$ in maximal diameter. This patient had a $2.3 \mathrm{~cm}$ non-functioning 
Table 3: Secreting adenoma type, growth control, and endocrine outcome

\begin{tabular}{lllllll}
\hline $\begin{array}{l}\text { Tumor } \\
\text { Type }\end{array}$ & Regression & Stability & LTFU & $\begin{array}{l}\text { Hormonal } \\
\text { Improvement }\end{array}$ & $\begin{array}{l}\text { Hormonal } \\
\text { Stability }\end{array}$ & $\begin{array}{l}\text { Hormonal } \\
\text { Progression }\end{array}$ \\
\hline GH & $6(30 \%)$ & $14(70 \%)$ & 1 & $9(40 \%)$ & $10(50 \%)$ & $1(10 \%)$ \\
\hline PRL & $3(42.9 \%)$ & $4(57.1 \%)$ & 1 & $5(71.4 \%)$ & $1(14.3 \%)$ & $1(14.3 \%)$ \\
\hline ACTH & $2(50.0 \%)$ & $2(50.0 \%)$ & 4 & $4(100 \%)$ & $0(0 \%)$ & $0(0 \%)$ \\
\hline LH/FSH & $2(100 \%)$ & 0 & 0 & $0(0 \%)$ & $2(100 \%)$ & $0(0 \%)$ \\
\hline
\end{tabular}

$\mathrm{GH}=$ Growth Hormone, $\mathrm{PRL}=$ Prolactin, $\mathrm{ACTH}=$ Adrenocorticotropic Hormone, $\mathrm{LH}=$ Luteinizing Hormone,

FSH $=$ Follicle Stimulating Hormone, LTFU $=$ Lost to Follow-Up

pituitary adenoma and received 13 Gy to the $50 \%$ isodose line. She described a post treatment headache as a transient complication. Her total follow-up at the time of this study being six months. Hormonal status has remained normal. Close imaging follow up has been recommended.

\section{Non-secreting Adenomas}

Of the 47 patients with non-functioning adenomas treated during our review period, four were lost to follow-up. The remaining patients demonstrated a 42 of 43 (97.7\%) tumor control rate, with $22(51.2 \%)$ showing regression, and 20 $(46.5 \%)$ showing tumor stability rates. Only one patient $(2.3 \%)$ in the non-functioning adenoma group had tumor growth despite treatment (as described previously).

\section{Secreting Adenomas}

We defined improved endocrine functioning as either being off hormonal modulating medication, or having reduced pre-GK medication doses. In addition, we defined endocrine stability as no change in pre-GK medication dosing after treatment. Results for individual tumor types are as follows:

\section{GH Adenomas}

There were 21 patients, with one lost to follow-up. Overall, $100 \%$ tumor control was achieved in those with follow up, with 6 of the $20(30 \%)$ patients displaying tumor stability, while the remaining $14(70 \%)$ demonstrated tumor regression. Average time to tumor regression for the $\mathrm{GH}$ adenomas was five months.

Nine $(45 \%)$ demonstrated improved hormonal functioning with 6 of $20(30 \%)$ having their pre-treatment medications discontinued. Three had reductions in medication. However, two of the patients with reduction of their pre-treatment medications developed panhypopituitarism secondary to GK and one became hypothyroid; all requiring pituitary hormone replacement therapy. Of the remaining 11 of the $20 \mathrm{GH}$ patients with followup, $10(50 \%)$ had endocrine stability or stable doses of their pretreatment medication continued, and one (10\%) had ongoing increasing GH and insulin growth factor-1 (IGF-1) levels despite treatment. One patient with endocrine stability became hypothyroid as a result of GK requiring thyroid supplementation.

\section{PRL Adenomas}

Of the eight patients with PRL secreting adenomas, one was lost to follow up. Tumor control for the remaining seven patients was achieved in 100\%, with three (42\%) displaying tumor stability, and four $(57 \%)$ having tumor regression. Average time until tumor regression in the PRL adenomas was 16.3 months.

Of those patients with PRL adenomas and follow-up, five (71.4\%) demonstrated improved hormone status, with three $(42.9 \%)$ coming off medication and having normalization of PRL levels, and two (28.6\%) patients achieving a decrease in their medication dosage. However, one patient achieving "medication free" status developed hypothyroidism post-GK requiring supplementation. One patient (14.2\%) had endocrine stability, and one (14.2\%) had endocrine progression despite treatment.

\section{ACTH Adenomas}

We had eight patients with ACTH secreting adenomas; four were lost to follow-up. Of those with follow up there was $100 \%$ tumor control, with two (50\%) having tumor stability, and two $(50 \%)$ displaying tumor regression. Average time until tumor regression in the ACTH adenomas was 10.5 months. Endocrine status of these adenomas improved in $100 \%$ of those with follow-up. Two (50\%) achieved reduction in medication dosage, while two $(50 \%)$ were free of their pre-operative medication as of their last visit.

\section{LH/FSH Adenomas}

Only two patients in our experience had LH/FSH secreting adenomas and neither was on hormonal modulating medications pre GK. Both patients had tumor control as of last follow-up, with one (50\%) displaying regression, noted at five months postGK, and the other having tumor stability. As well, both patients achieved stable LH/FSH levels post treatment and were classified as endocrinologically stable. Neither achieved hormonal normalization.

A summary of the tumor control and endocrine function outcome is summarized in Table 3. 


\section{Complications}

We divided our complications into transient minor complications, and serious permanent complications. Overall 31 of the 76 patients $(34.2 \%)$ had transient complications, and 14 $(18.4 \%)$ had serious permanent complications.

The transient complications for all tumor types included: pin site swelling (17), pin site infection (1), pin site dysesthesias (5), visual blurring (4), short term memory loss (2), and ataxia (1). All of these had resolved as of last follow-up. Transient complications in the secreting adenomas included: pin site swelling (6), pin site dysesthesias (2), and ataxia (1).

Serious permanent complications for all tumor types included: panhypopituitarism (4), hypothyroidism (4), hypocortisolemia (1), diabetes insipidus (1), apoplexy (1), visual field defect secondary to radiation induced optic neuropathy (2), and diplopia (1). All patients with new pituitary axis abnormalities post-GK required hormonal replacement, which they were on as of last follow-up, making our post-GK pituitary dysfunction rate $13.2 \%$. The patient with apoplexy post-GK had a $3.3 \mathrm{~cm}^{3}$ adenoma treated with 15 Gy to the $50 \%$ isodose line. He developed headache and visual blurring five days post gamma knife, with radiographic evidence of hemorrhage consistent with apoplexy. He was taken to the operating theater for transsphenoidal resection due to mass effect on the optic apparatus and visual deterioration. As of last follow-up the patient still has a minor visual field deficit.

Radiation induced optic neuropathy was observed in two patients, leading to permanent visual field defects. One patient had a $4.06 \mathrm{~cm}$ GH pituitary adenoma with encroachment on the chiasm. He had previous transsphenoidal and transcranial resection due to optic apparatus distortion, with a mild preoperative right eye temporal visual field defect. Gamma Knife SRS was elected as a treatment option considering the patient had failed both transsphenoidal and transcranial debulking, in addition to external beam radiation in the past. Gamma Knife treatment consisted of $20 \mathrm{~Gy}$ to the $50 \%$ isodose line, and a maximal recorded $\mathrm{ON}$ dose of $8 \mathrm{~Gy}$. The patient developed a bitemporal field cut. On MRI the chiasm looked atrophic at six months post-GK. His symptoms started nine months post-GK. The second patient had a $3.47 \mathrm{~cm}$ non-secreting pituitary adenoma with suprasellar and right cavernous sinus extension and encroachment on the optic nerves, leading to right eye ophthalmoplegia. He had failed both transsphenoidal resection and external beam radiation. GK treatment consisted of a dose of $15 \mathrm{~Gy}$ to the $50 \%$ isodose line, with a maximal recorded ON dose of 9 Gy. During a follow-up visual field analysis 24 months post-GK, a left eye temporal field loss was noticed. This was not noticed by the patient. No specific abnormality of the optic apparatus could be identified on MRI.

Finally, diplopia developed post-GK in one patient who was treated for $3.79 \mathrm{~cm}$ non-secreting pituitary adenoma with suprasellar and right cavernous sinus extension. A 13 Gy dose to the $50 \%$ isodose line was administered. Diplopia was noted at the 3 month follow up on superior gaze. In addition mild right ptosis was noted, indicating a partial third nerve etiology. This deficit has been persistent since.

For the secreting pituitary adenomas, the serious permanent complications included: hypocortisolemia (1), panhypopituitarism
(3), hypothyroidism (2), radiation induced optic neuropathy (1), and diabetes insipidus (1).

\section{Discussion}

Gamma Knife treatment has been described in the literature to result in tumor growth control rates ranging up to $92-100 \%$ for adenomas of all types ${ }^{2,3}$. Endocrine stabilization or improvement for those tumors with secreting status varies depending on tumor subtype, with average remission rates for GH, PRL, and ACTH adenomas having been described as $0-67 \%^{1-5}, 0-84 \%^{1,2,6,7}$, and $10-100 \%^{1,2}$ respectively. Long-term growth control has been described in up to $83 \%$ at 80 months $^{8}$. Extended follow-up at a mean of 54 months for functioning pituitary adenomas post-GK in the literature demonstrates the chance of endocrinologic remission at $87 \%$ for $\mathrm{ACTH}, 67 \%$ for $\mathrm{GH}$, and $18 \%$ for PRL adenomas ${ }^{9}$.

Overall our experience of a tumor growth control rate of $98.6 \%$ for all adenoma types is comparable to that found in the literature $^{1,2}$. Our results for growth control of non-secreting adenomas are within the literature experience ${ }^{1,2,10}$ at $97.7 \%$. We attribute this to lessons learned from the literature including recommendations to maintain a dose between $12-18 \mathrm{~Gy}$ at the $50 \%$ isodose line for non-secreting tumors ${ }^{10}$. Our growth control rates of $100 \%$ for secreting adenomas are within the literature range described ${ }^{1-9}$. We had four ACTH, one GH and one PRL patients lost to follow-up, however, and the overall tumor control rates may be less than we report here.

We had a relatively large proportion of $\mathrm{GH}$ adenomas in our patient population. This may be related to the local good tumor control rates for PRL adenomas and ACTH adenomas with standard transsphenoidal techniques and medical management. Our control of the GH adenomas is slightly better than that described $^{1-5}$, despite losing one patient to follow-up. Cessation of hormone modulating medications pre- $\mathrm{GK}^{10}$, and adherence to literature standards in dosing secreting adenomas ${ }^{11}$ has allowed us to achieve this.

Our endocrine improvement and stability rates (see Table 3) for those patients with secreting adenomas are also within literature limits described above. For GH adenomas, our endocrine improvement rate of $45 \%$ and stability rate of $50 \%$ is slightly higher that described in the literature ${ }^{1-5}$. This is despite the majority displaying cavernous sinus extension, which has been described as a negative predictor of remission ${ }^{4}$. We again believe this stems from diligence with pre-operative medication cessation and dose prescription. Similarly our ACTH adenomas and PRL adenomas displayed endocrine improvement/stability rates of $71.4 \% / 28.6 \%$, and $50 \% / 50 \%$ respectively. However, as previously mentioned six patients with functioning adenomas were lost to follow-up. Furthermore, two patients displaying hormonal regression developed panhypopituitarism while one developed hypothyroidism post-GK. As well, two patients with hormonal stability of their secreting adenomas developed hypothyroidism post-GK. Thus, despite positive endocrine outcomes in terms of tumour function, some traded one pituitary axis problem for another as a result of dysfunction secondary to radiosurgery.

The total number of patients with previous documented surgical intervention for their pituitary adenomas is small at $65 \%$, relative to other series, and represents the ongoing success 
with surgical treatment of pituitary adenomas. As well, the large proportion of patients without previous surgery demonstrates an institutional shift in our multi-modality treatment approach to pituitary adenomas, utilizing GK in some earlier in the disease process before surgery is necessary. Comparing those patients with previous surgery to those treated with GK as their first procedure, $55(98 \%)$ patients versus $20(100 \%)$ patients had tumor control respectively. For those patients with previous surgical resection and tumor control post-GK, 26 (46\%) displayed decrease in size, while 29 (52\%) demonstrated stability in size. In those patients without previous surgical attempts, $16(80 \%)$ demonstrated tumor regression, while four $(20 \%)$ demonstrated stability in size. Twenty-five patients with previous attempt at surgical resection had secreting tumors. The endocrine outcome for this group included: Improved hormonal status in $11(44 \%)$, stable endocrine status in $13(52 \%)$, and progression in $1(4 \%)$. The nine patients with secreting tumors and without previous surgery displayed improved hormonal status in six (67\%), stability in two $(22 \%)$, and progression in one $(11 \%)$. Given the overall tumor regression rate and improved hormonal status for secreting ademonas in the "no-surgery" group compared to the "previous-surgery" group, one could argue that GK radiosurgery as a primary treatment modality in pituitary tumors is a reasonable option to consider and requires future investigation. However, we acknowledge the disparity in numbers between the groups, and the small overall numbers in general. In addition, the comparatively improved hormonal and tumor regression rates we have experienced are likely related to the complex treatment refractory nature of the tumors in the "previous-surgery" group, hence why these patients have undergone multiple medical and surgical failures prior to GK.

Our complications were higher than described in the literature. We had 31 patients with transient minor complications. On further breakdown, the majority (74.2\%) were stereotactic frame related and most literature sources do not describe these. If we exclude these, only seven patients had transient complications, all which completely resolved.

The permanent complication rate of $18.4 \%$ was predominantly secondary to pituitary axis dysfunction. Overall our pituitary axis dysfunction in 10 of 76 (13.2\%) patients, is well within the limits described ${ }^{1,2}$. The majority of the serious permanent complications, 8 of $14(57.1 \%)$, occurred in the secreting adenomas. Of these, the majority of the pituitary axis dysfunction, 7 of the $10(70.0 \%)$ described, post-GK occurred in the secreting ademona population. Despite this, the objective in treatment planning should be to minimize this outcome in SRS, and so continue to keep the stalk and distal infundibular dose less than $15 \mathrm{~Gy}$, where possible, in order to reduce this post SRS complication $^{12-15}$. We had one unfortunate patient with pituitary apoplexy within five days of treatment. It is unclear that GK was the cause, as the relationship of apoplexy to GK is not clear and since radiation effects are rarely so acute.

The two patients with radiation induced optic neuropathy were of concern. Both of these patients had ON dosing under 10 Gy, and were within the 12 Gy limit recommended by Stafford et $\mathrm{al}^{16}$ and even the 10 Gy dose as recommended by earlier literature ${ }^{17,18}$. This is just slightly above the literature rate of radiation induced $\mathrm{ON}$ at $2.6 \%$ compared to less than $2 \%{ }^{16}$. We found that both of these patients had significant suprasellar extension with optic apparatus deformation prior to the surgical debulking performed at pre-GK intervals of 10 and 205 months respectively. No MRI evidence of optic nerve compression secondary to tumour growth post-GK was found. We believe this previous compression of the optic apparatus predisposed these patients to radiation induced optic neuropathy in the setting of ON dosing less than 10 Gy. Finally, the one patient with new onset diplopia was likely related to cavernous sinus radiation dosing that led to a 6th nerve radiation neuropathy despite maintaining low cavernous sinus dosing as recommended ${ }^{19}$.

Permanent complications for the secreting adenomas were higher, with 8 of the 14 permanent complications occurring in the secreting group. Of interest is the high proportion of pituitary dysfunction, 7 of the 10 cases described occurred in the secreting adenoma group. This is likely related to larger infundibular doses seen secondary to the higher marginal dose required for tumor and endocrine control.

We recognize this study has several limitations. First, ten patients were lost to follow-up. Second, a large portion of the ACTH secreting adenomas were lost to follow-up, making the tumor growth and endocrine outcomes in that category of patients difficult to interpret. Third, the retrospective nature of the study left some follow up data difficult to obtain. Finally, the small patient population makes these results difficult to generalize to all pituitary adenomas treated with GK SRS.

Overall we believe good results can be achieved by the following: First, follow literature recommended $50 \%$ isodose line dosing for non-secreting and secreting tumors at $12-18 \mathrm{~Gy}$ and 18-30 Gy respectively ${ }^{11}$. Second, attempts at maintaining infundibular and stalk dosing as low as possible to prevent postGK hypopituitarism ${ }^{12,13}$ should be made, though adequate tumor dosing remains the primary goal. Third, instruct patients to stop taking their hormone modulating medications prior to GK in order to maximize endocrine remission in functioning adenomas $^{10,11}$. Fourth, strive to keep ON dosing under 10 Gy to reduce the risk of radiation induced $\mathrm{ON}$ as described in the literature $^{16-18}$, though tolerances up to 12 Gy have been described. Finally, limit the parasellar radiation dosing (less than 19 Gy if possible) to reduce the risk of other radiation induced cranial neuropathies ${ }^{20,21}$.

\section{Conclusion}

Gamma Knife stereotactic radiosurgery offers a relatively safe and effective means of achieving both tumor growth control and endocrine remission and stability in pituitary adenomas. With the advent of SRS and the implementation of this tool in the treatment of pituitary adenomas, those patients with residual or recurrent disease, and those medically unfit for surgery have a less invasive radiosurgical option to achieve tumor growth control and, potentially, improvement in hormonal status. 


\section{REFERENCES}

1. Witt TC. Stereotactic radiosurgery for pituitary tumors. Neurosurg Focus. 2003;14(5):E10.

2. Jagannathan J, Yen CP, Pouratian N, Laws ER, Sheehan JP. Stereotactic radiosurgery for pituitary adenomas: a comprehensive review of indications, techniques and long-term results using the Gamma Knife. J Neurooncol. 2009;92:345-56.

3. Yang I, Kim W, De Salles A, Bergsneider M. A systemic analysis of disease control in acromegaly treated with radiosurgery. Neurosug Focus. 2010; 29(4):E13.

4. Poon TL, Leung SML, Poon CYF, Yu CP. Predictors of outcome following gamma knife surgery for acromegaly. J Neurosurg. 2010;113:149-52.

5. Stapleton CJ, Liu CY, Weiss MH. The role of stereotactic radiosurgery in the multimodal management of growth hormone - secreting pituitary adenomas. Neurosurg Focus. 2010;29 (4):E11.

6. Tanaka S, Link MJ, Brown PD, Stafford SL, Young WF, Pollock BE. Gamma knife radiosurgery for patients with prolactinsecreting pituitary adenomas. World Neurosurg. 2010;74(1): 147-52.

7. Jezkova J, Hana V, Krsek M, et al. Use of the leksell gamma knife in the treatment of prolactinoma patients. Clin Endocrinol. 2009; 70:732-41.

8. Gopalan R, Schlesinger D, Vance ML, Laws E, Sheehan J. Longterm outcomes after gamma knife radiosurgery for patients with a non-functioning pituitary adenoma. Neurosurgery. 2011; 69(2): 284-93.

9. Pollock BE, Brown PD, Nippoldt TB, Young WF. Pituitary tumor type affects the chance of biochemical remission after radiosurgery of hormone-secreting pituitary adenomas. Neurosurgery. 2008;62(6):1271-8.

10. Pollock BE, Nippoldt TB, Stafford SL, Foote RL, Abboud CF. Results of stereotactic radiosurgery in patients with hormoneproducing adenomas: factors associated with endocrine normalization. J Neurosurg. 2002;97:525-30.

11. Sheehan JP, Pouratian N, Steiner L, Laws ER, Vance ML. Gamma knife surgery for pituitary adenomas: factors related to radiological and endocrine outcomes. J Neurosurg. 2011;114: $303-9$.
12. Feigl GC, Bonelli CM, Berghold A, Mokry M. Effects of gamma knife radiosurgery of pituitary adenomas on pituitary function. $\mathrm{J}$ Neurosurg. 2002;97(suppl 5):415-21.

13. Marek J, Jezkova J, Hana V, et al. Is it possible to avoid hypopituitarism after irradiation of pituitary adenomas by the leksell gamma knife? Eur J Endocrinology. 2011;164:169-78.

14. Feigl GC, Pistracher K, Berghold A, Mokry M. Pituitary insufficiency as a side effect after radiosurgery for pituitary adenomas: the role of the hypothalamus. J Neurosurg. 2010;113: 153-9.

15. Leenstra JL, Tanaka S, Kline RW, et al. Factors associated with endocrine deficits after stereotactic radiosurgery of pituitary adenomas. Neurosurgery. 2010;67(1):27-33.

16. Stafford SL, Pollock BE, Leavitt JA, et al. A study on the radiation tolerance of the optic nerves and chiasm after stereotactic radiosurgery. Int J Radiation Oncology Biol Phys. 2003:55(5): 1177-81.

17. Tishler RB, Loeffler JS, Lunsford LD, et al. Tolerance of cranial nerves of the cavernous sinus to radiosurgery. Int J Radiat Onc Biol Phys. 1993;27(2):215-21.

18. Leber KA, Berglöff J, Pendl G. Dose-response of the visual pathways and cranial nerves of the cavernous sinus to stereotactic radiosurgery. J Neurosurg. 1998; 88:43-50.

19. Jagannathan J, Yen CP, Pouratian N, et al. Stereotactic radiosurgery for pituitary adenomas: a comprehensive review of indications, techniques and long-term results using Gamma Knife. J Neurooncol. 2009;92:345-56.

20. Morita A, Coffey RJ, Foote RL, Schiff D, Gorman D. Risk of injury to cranial nerves after gamma knife radiosurgery for skull base meningiomas: Experience in 88 patients. J Neurosurg. 1999;90: 42-9.

21. Tishler RB, Loeffler JS, Lunsford LD, et al. Tolerance of cranial nerves of the cavernous sinus to radiosurgery. Int J Radiat Onc Biol Phys. 1993;27(2):215-21. 